\title{
Evaluation of cyclic efficiency of multilayer desiccant bed column
}

\author{
Prueksa Sawardsuk ${ }^{1}$, Jiraporn Sripinyowanich Jongyingcharoen ${ }^{2}$, and Ekkapong \\ Cheevitsopon ${ }^{1 *}$ \\ ${ }^{1}$ King Mongkut's Institute of Technology Ladkrabang, Department of Food Engineering, Faculty of \\ Engineering, , Bangkok, Thailand \\ ${ }^{2}$ King Mongkut's Institute of Technology Ladkrabang, Department of Agricultural Engineering, \\ Faculty of Engineering, Bangkok, Thailand
}

\begin{abstract}
The main objective was to evaluate cyclic efficiency of a multilayer desiccant bed column. The experimental setup consisted of an air humidifier unit, a heating unit for regeneration, and the desiccant bed column with 15 layers. An airflow rate of $2.4 \mathrm{~m}^{3} / \mathrm{min}$ with the humidity ratio of $20 \mathrm{~g}$ water $/ \mathrm{kg}$ dry air was used in this study. The results showed that the highest dehumidification rate of $21 \mathrm{~g}$ water/min was found at the beginning of the dehumidification process. During the regeneration process, the highest regeneration rate was $39 \mathrm{~g}$ water/min when regenerating the desiccant at a temperature of $90^{\circ} \mathrm{C}$. For cyclic operation process, the cyclic efficiencies were $11 \%$ and $7 \%$ at the regeneration temperatures of $70^{\circ} \mathrm{C}$ and $90^{\circ} \mathrm{C}$, respectively. The cyclic efficiency was dependent on the regeneration temperature.
\end{abstract}

\section{Introduction}

Methods to dehumidify air are mainly into 2 ways: the moisture are condensed on the surface of cooling coil which is the refrigeration method, and the moisture are absorbed by desiccant material which is sorption method. Dehumidification using desiccant materials is widely used in industrial process. Dehumidifier in the form of desiccant beds is used in many applications, such as chemical materials separation, and food industries [1]. In the past few years, a number of dehumidifier applications with food and agriculture products have been conducted such as drying of fenugreek green, spray drying of tomato pulp [2, 3, 4]. Silica gel, activated alumina, zeolites, and molecular sieve are the most common solid desiccant [5]. Many investigators have studied in air characteristics during adsorption and desorption process of dehumidifiers. Adsorption capacity depend on the temperature and time of regeneration. An increase in adsorption capacity is found with increase in regeneration temperature and/or regeneration time $[6,7]$. Desorption rate increases with increase in inlet air temperature [8]. Air dehumidifier using desiccant bed cannot run without regenerating process of desiccant material. Dehumidification (adsorption) and regeneration (desorption) is required in order to make the process work continuously. From the study reveal, the cyclic operation of

Corresponding author: ekkapong.ch@kmitl.ac.th 
dehumidifier studies have little work. Ramzy et al. [9] studied parameters that affect the cyclic operation of radial flow desiccant bed dehumidifier. It found that humidity of dehumidified air decrease with increase in regeneration temperature. Adsorption time increase as the regeneration temperature increase. Reducing inlet air temperature result in the ability of the bed to adsorb from air increase. Two packed beds of silica gel were utilized to dehumidify air and investigate on the cyclic operation [5]. The mathematical model has been validated using the experimental data. The maximum cycle efficiency was found at regeneration temperature $90-95^{\circ} \mathrm{C}$ when bed length were between 50 to $300 \mathrm{~mm}$. Increasing temperature of regeneration air exceeds the optimum value does not result in the better dehumidification rate and the cycle efficiency decreases. Banghapour et al. [6] studied the performance of a desiccant dehumidification column under cyclic operating conditions. Cold air and hot air were used for adsorption and regeneration. The water uptake of the desiccant column was calculated. Increasing cycle time leads to increase water uptake. The system works better and greater adsorption when increasing regeneration temperature. The effectiveness of the desiccant column was improved by increasing the hot air velocity. Rogala et al. [10] studied adsorption and desorption characteristics of the fluidised desiccant cooler. They reported that the switching time between adsorption and desorption had a greater impact on the water uptake of bed. The optimum switching time was $350 \mathrm{~s}$ If using switching time lower than optimum value, the hot air for desorption was not properly utilized. If switching time higher than optimum value, it did not significantly improve the desorption but the adsorption was improved. In this work, the cycle time of multilayer desiccant bed column was estimated by the experimental data from single blow of dehumidification and regeneration. Average water removal (dehumidification) rate and regeneration rate were parameters that used in the cycle time selection. The cyclic operation was tested and monitor air humidity ratio of outlet air.

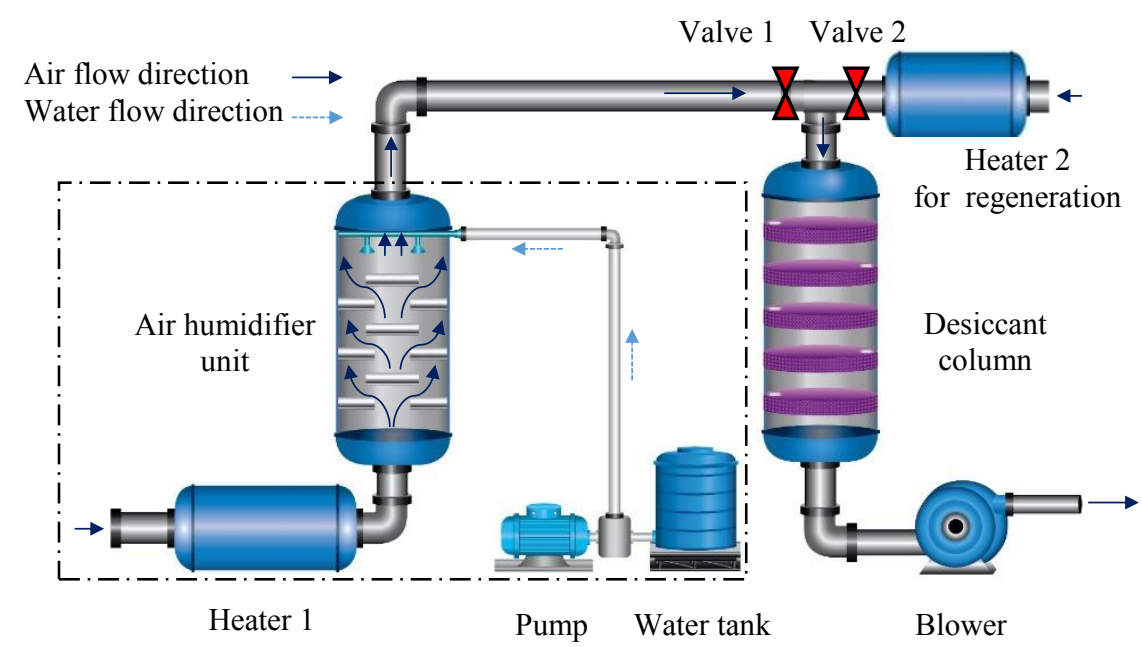

Fig. 1. A schematic diagram of the multilayer desiccant bed column test unit.

\section{Experimental setup}

Figure 1 shows the system of the multilayer desiccant bed column test unit. The test unit was composed of a desiccant column and an air humidifier unit. The inner diameter of the 
desiccant column was $20 \mathrm{~cm}$ and 15 layers of desiccant bed containers were stacked inside. At the bottom of the container was a sieve. An air duct with a diameter of $2.54 \mathrm{~cm}$ to allow the air to pass through and between the layers of desiccant container was set at one side of its. The duct in the container was placed alternately on the left and switch to the right side of the succeeding desiccant bed layers. Hence the air flow direction in the desiccant column was a zigzag flow pattern. Humidifier unit was used to adjusted humidity of ambient air by spraying water. Dehumidification test were done by the ambient air pass through the air humidifier unit to adjust humidity ratio before the air was flown in to the desiccant column. Regeneration processes were done by the ambient air pass through the air humidifier unit to adjust humidity and heated to the desired temperature before the air flow in to the desiccant column.

\section{Analysis of cyclic efficiency}

Commercial silica gel size 2-4 mm. were used in this experiment (Power dry, Thailand). Silica gel was dried at $120^{\circ} \mathrm{C}$ for 12 hours [11] and kept in a close chamber until use. The moisture content of the silica gel was determined with an infrared moisture analyser (MA45 Sartorius, Germany). Silica gel was packed in the desiccant column at $1950 \mathrm{~g}$. Silica gel was portioned out equally to each layer in the column. Dehumidification process, inlet air with humidity ratio $20 \mathrm{~g}$ water $/ \mathrm{kg}$ dry air was dehumidified at an air flow rate of $2.4 \mathrm{~m}^{3} / \mathrm{min}$. Regeneration process, silica gel with moisture content about $15 \% \mathrm{db}$ were regenerated by hot air at an air flow rate of $2.4 \mathrm{~m}^{3} / \mathrm{min}$. Temperature of hot air was $70^{\circ} \mathrm{C}$ and $90^{\circ} \mathrm{C}$. The hot air stream temperature was maintained at the desired temperature before starting the experiment. The relative humidity and temperature of the inlet and outlet air were monitored throughout the experiment with a temperature hygrometer (KT320 KIMO, France).

Dehumidification rate and regeneration rate were the factor to decide the time of cyclic operation. Cyclic operation on a single multilayer desiccant bed column was tested by switching between dehumidification and regeneration with helping of valve 1 and 2 . Ambient air was used to test the cyclic process at an air flow rate $2.4 \mathrm{~m}^{3} / \mathrm{min}$. An amount of adsorbed water and desorbed water were calculated to determine the cyclic operation time.

The difference of outlet humidity ratio between dehumidification and regeneration $\Delta w$ was calculated, as in Equation (1).

$$
\Delta w=w_{o}-w_{i}
$$

Dehumidification rate and regeneration rate were determined as the product of the mass flow rate and humidity ratio difference between the inlet and outlet air of the multilayer desiccant bed column, as in Equation (2) and (3) [12].

$$
\begin{aligned}
\text { Dehumidificaion rate } & =(\dot{m})\left(w_{i, d}-w_{o, d}\right) \\
\text { Regeneration rate } & =(\dot{m})\left(w_{o, r}-w_{i, r}\right)
\end{aligned}
$$

Where, $\dot{m}$ is the mass flow rate of air ( $\mathrm{kg}$ dry air/min); $w_{i}$ is the humidity ratio of inlet air and $w_{o}$ is the humidity of the outlet air ( $\mathrm{g}$ water/kg dry air); subscript $\mathrm{d}$ is the dehumidification; and subscript $r$ is the regeneration.

The cyclic efficiency is defined as follows [5],

$$
\eta=\frac{\int L H \times \dot{m}_{d}\left(w_{i, d}-w_{o, d}\right) d t}{\int c_{a} \times \dot{m}_{r}\left(T_{a i, r}-T_{a m b}\right) d t} \times 100
$$

Where, LH is latent heat of the vapor; $c_{a}$ is specific heat of air; $T_{a i, r}$ is temperature of regenerating air and $T_{a m b}$ is temperature of ambient air. 


\section{Results and discussion}

\subsection{Dehumidification process}

The inlet air at ambient condition was passed the humidifier unit to adjust air temperatures of $30-32^{\circ} \mathrm{C}$ and relative humidity of $67-73 \%$. After humidifying, the humidity ratio of air was controlled to be approximately $20 \pm 0.36 \mathrm{~g}$ water/ $\mathrm{kg}$ dry air before a study of dehumidification and regeneration process in the multilayer desiccant bed column.

Humidity ratio changes of outlet air during dehumidification process are presented in Figure 2. It can be seen that the humidity ratio of outlet air sharply decreased at the beginning of dehumidification period. Then, it significantly increased within the $30 \mathrm{~min}$ of process, and slowly converges to a humidity ratio of inlet air after prolonged dehumidification. The rapid absorption of desiccant at an initial period was because vapor pressure on the desiccant surface is less than the vapor pressure of experimental air. [13] The vapor pressure difference between desiccant surface and air steadily reduced with time. The maximum dehumidification rate was found to be $21.06 \mathrm{~g}$ water/min during the first period and decreased continually with time as shown in Figure 3. It indicated that changes in the dehumidification rate exhibited two distinct periods, namely, significant decreasing, and slight decreasing period.

\subsection{Regeneration process}

The humidified air was heated to 70 , and $90^{\circ} \mathrm{C}$ by a heater 2 to regenerate the moist desiccant in the multilayer desiccant bed column. Figure 2 shows the changes in humidity ratio of outlet air during generation process. The humidity ratio of outlet air dramatically increased until reaching the highest value because of increasing temperature in desiccant. And then, the humidity ratio decreased gently in later stages because the moisture content in desiccant decreases. Figure 3 illustrates the changes in regeneration rate undergoing different regeneration temperatures. It was found that regeneration behaviour exhibited two distinct periods, namely, increasing rate, and decreasing rate period. The highest regeneration rates were 27.24 and $39.17 \mathrm{~g}$ water/min for the regeneration temperatures of 70 , and $90^{\circ} \mathrm{C}$, respectively.

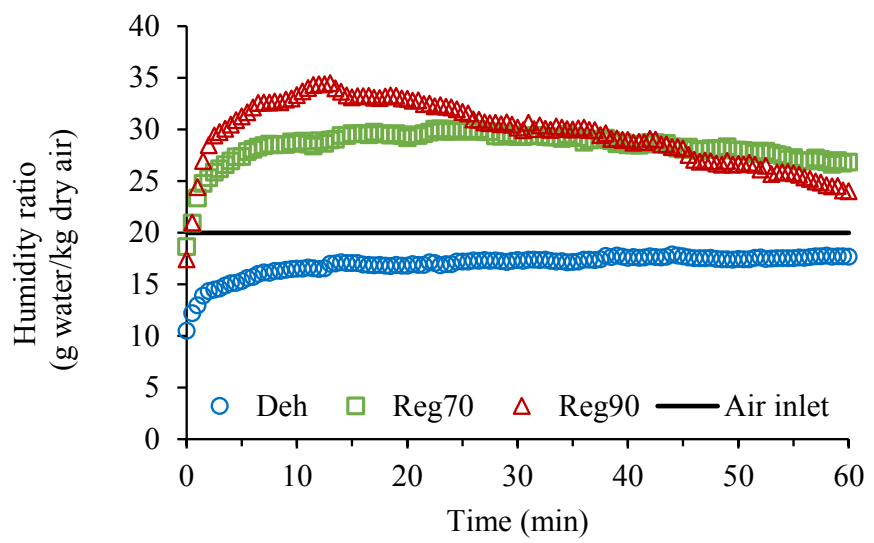

Fig. 2. Humidity ratio of outlet air during dehumidification (Deh) and regeneration rate at $70^{\circ} \mathrm{C}$ (Reg70) and $90^{\circ} \mathrm{C}(\operatorname{Reg} 90)$. 


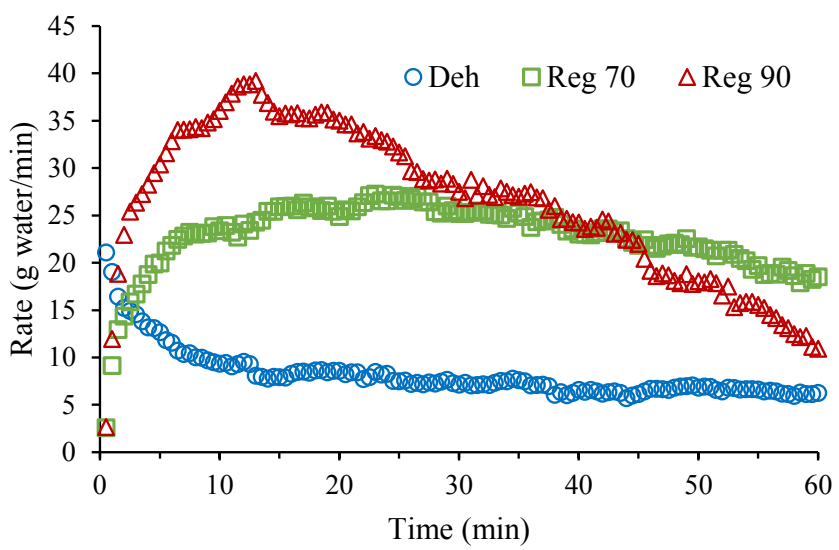

Fig. 3. The dehumidification rate $\left(\right.$ Deh) and regeneration rate at $70^{\circ} \mathrm{C}(\operatorname{Reg} 70)$ and $90^{\circ} \mathrm{C}(\operatorname{Reg} 90)$.

\subsection{Cyclic efficiency}

Cyclic operation of the multilayer desiccant bed column is the continuous dehumidification and regeneration cycles of silica gel. Thus, the cyclic time consists of one cycle of the dehumidification time and regeneration time. The regeneration time for a complete cycle is the time required to remove an amount of absorbed water in desiccant during the dehumidification process. In this study, the regeneration time for a complete cycle was considered to be $10 \mathrm{~min}$ and the cyclic time was $20 \mathrm{~min}$.

An inlet air humidity of about $15-16 \mathrm{~g}$ water $/ \mathrm{kg}$ dry air was feed into the multilayer desiccant bed column. The cycle started with dehumidification mode for $10 \mathrm{~min}$ with subsequent $10 \mathrm{~min}$ for regeneration, so one cycle takes $20 \mathrm{~min}$. The cyclic processes were run continuously for $60 \mathrm{~min}$. Changes in outlet air humidity ratio during the cyclic operation undergoing different regeneration temperatures were shown in Figure 5 and Figure 6. It was observed that the humidity ratios of outlet air during dehumidification process were not significantly different when desiccant was regenerated at the air temperatures of $70^{\circ} \mathrm{C}$ and $90^{\circ} \mathrm{C}$. However, trends of outlet air humidity ratio during the regeneration process increased with an increase in regeneration temperature.

For the second and the third cycles, the dehumidification process began after starting the cycles for a moment. Humidity ratio dropped instantly at the first minute of the cycle because the direction of air inlet valves were changed. Similar characteristics were also observed in packed bed and radial flow bed [5,9]. Moisture ratio of ambient air was reduced by about 2.5 $\mathrm{g}$ water/kg dry air which was lower than the previous dehumidification test because air inlet humidity ratio observed in the cyclic operation was lower. Both regeneration temperatures can regenerate silica gel and make the system work continuously.

For the efficiency analysis during the cyclic operation, the regeneration process using hot air at $70^{\circ} \mathrm{C}$ and $90^{\circ} \mathrm{C}$ had the efficiency values of $11 \%$ and $7 \%$, respectively. Regeneration rate at $90^{\circ} \mathrm{C}$ was higher than that at $70^{\circ} \mathrm{C}$ while the cyclic efficiency of the former was lower. More energy was required to raise higher regeneration temperature while the outlet air humidity ratios of both temperatures were nearly equal. This result agreed with Ramzy et al. [5], efficiency of the dehumidification systems reached the maximum value at the optimum regeneration temperature. If regenerating air temperature was higher than the optimum value, it did not increase the dehumidification rate and caused lower cyclic operation efficiency. 


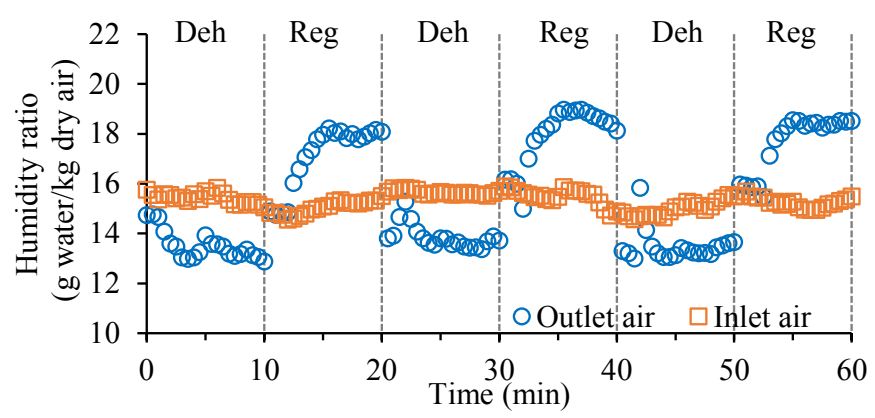

Fig. 5. Variation of humidity ratio of cyclic operations with regeneration temperature of $70^{\circ} \mathrm{C}$ (Deh: Dehumidification, Reg: Regeneration).

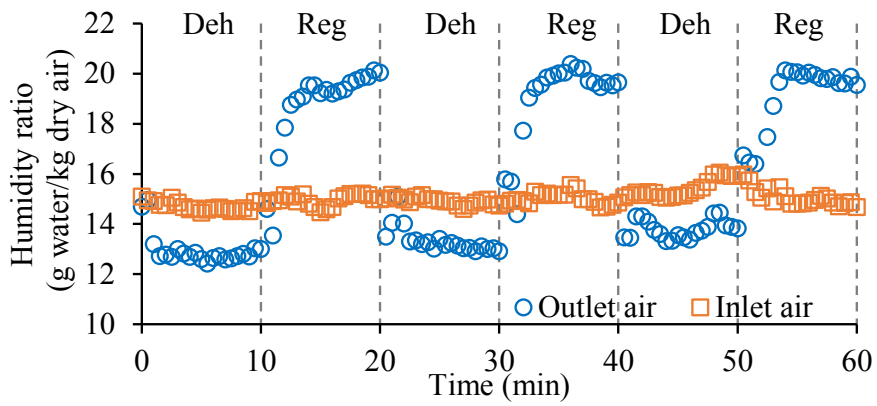

Fig. 6. Variation of humidity ratio of cyclic operations with regeneration temperature of $90^{\circ} \mathrm{C}$ (Deh: Dehumidification, Reg: Regeneration).

\section{Conclusions}

Changes in humidity ratio of outlet air during the dehumidification and regeneration process were studied. When the multilayer desiccant bed column was operated in a cyclic process of alternate dehumidification and regeneration, the cyclic efficiency was analyzed. The following conclusion can be summarized:

1. The maximum dehumidification rate was $21.06 \mathrm{~g}$ water/min at the beginning of dehumidification process. Dehumidification rate decreased with time.

2. During the regeneration process, the maximum regeneration rates were $27.24 \mathrm{~g}$ water/min at the regeneration temperature of $70^{\circ} \mathrm{C}$ and $39.17 \mathrm{~g}$ water $/ \mathrm{min}$ at the regeneration temperature of $90^{\circ} \mathrm{C}$.

3. In the cyclic operation, the highest cyclic efficiency was obtained at the regeneration temperature of $70^{\circ} \mathrm{C}$. It indicated that the regeneration temperature had an effect on the cyclic efficiency.

This research project was supported by the National Research Council of Thailand, fiscal year of 2016.

\section{References}

1. M.M. Awad, A. K. Ramzy, A.M. Hamed, H.M. Bekheit, Appl. Therm. Eng 28, 75 (2008)

2. A. M. Goula, K. G. Adamopoulos, J Food Eng 66, 25 (2005).

3. A. K. Attkan, N. Kumar, Y. K. Yadav, IOSR-JESTFT 8, 43 (2014)

4. M. Djaeni, D. A. Sari, Procedia Environment Science 23, 2 (2015) 
5. A. K. Ramzy, R. Kadoli, A. Babu T. P., Energy 56, 8 (2013)

6. B. Baghapour, M. Rouhani, M. Bahrami, Experimental design and performance analysis of a desiccant dehumidification column under cyclic operating conditions, in Proceedings of the IX Minsk International Seminar "Heat Pipes, Heat Pumps, Refrigerator, Power Sources", 7 -10 Sep 2015, Minsk, Belarus (2015)

7. K. S. Chang, H. C. Wang, T. W. Chung, Appl. Therm. Eng 24, 735 (2004)

8. A. E. Kabeel, RENEW ENERG 34, 255 (2009)

9. A. K. Ramzy, A. M. Hamed, M. M. Awad, M. M. Bekheit, JETR 2, 96 (2010)

10. Z. Rogala, P. Kolasinski, P. Blasiak, Energies 11, 1597 (2018)

11. M. A. Rady, Heat Mass Transfer 45, 545 (2009)

12. W. Yang, H. Deng, Z.Wang, X. Zhao, S. He, Energies 10, 1369 (2017)

13. A.M. Hamed, W.R. Abd-Elrahman, S.H. El-Emam, M.M. Awad, Energy Convas Manag 65, 262 (2013)

14. S.K. Yeboah, J. Darkwa, Renew. Sustain. Energy Rev. 58, 1500 (2016) 